\title{
Renewable Energy Equivalent Footprint (REEF): A Method for Envisioning a Sustainable Energy Future
}

\author{
James Ward ${ }^{1, *}$, Steve Mohr ${ }^{2}$, Robert Costanza ${ }^{3}$, , Paul Sutton ${ }^{3,4}$ and Luca Coscieme ${ }^{5}$ \\ 1 Science, Technology, Engineering \& Mathematics (STEM), University of South Australia, \\ Adelaide 5001, Australia \\ 2 Research and Innovation Services, University of Newcastle, Newcastle 2308, Australia; \\ steve.mohr@newcastle.edu.au \\ 3 Crawford School of Public Policy, Australian National University, Canberra 2601, Australia; \\ rcostanz@gmail.com (R.C.); paul.sutton@du.edu (P.S.) \\ 4 Department of Geography and the Environment, University of Denver, Denver, CO 80208, USA \\ 5 School of Natural Sciences, Trinity College Dublin, D02 PN40 Dublin, Ireland; lucaaq@gmail.com \\ * Correspondence: james.ward@unisa.edu.au; Tel.: +61-8-8302-3128
}

Received: 10 September 2020; Accepted: 20 November 2020; Published: 24 November 2020

\begin{abstract}
We present an alternative approach to estimating the spatial footprint of energy consumption, as this represents a major fraction of the ecological footprint $(E F)$. Rather than depicting the current lack of sustainability that comes from estimating a footprint based on uptake of carbon emissions (the method used in EF accounting), our proposed "Renewable Energy Equivalent Footprint" (REEF) instead depicts a hypothetical world in which the electricity and fuel demands are met entirely from renewable energy. The analysis shows that current human energy demands could theoretically be met by renewable energy and remain within the biocapacity of one planet. However, with current technology there is no margin to leave any biocapacity for nature, leading to the investigation of two additional scenarios: (1) radical electrification of the energy supply, assuming $75 \%$ of final energy demand can be met with electricity, and (2) adopting technology in which electricity is used to convert atmospheric gases into synthetic fuel. The REEF demonstrates that a sustainable and desirable future powered by renewable energy: (i) may be possible, depending on the worldwide adoption of consumption patterns typical of several key exemplar countries; (ii) is highly dependent on major future technological development, namely electrification and synthetic fuels; and (iii) is still likely to require appropriation of a substantial, albeit hopefully sustainable, fraction of the world's forest area.
\end{abstract}

Keywords: ecological footprint; renewable energy; carbon emissions; biocapacity

\section{Introduction}

The state of the world's environment is widely acknowledged to be declining [1], with rising temperatures driving global climate change and various planetary boundaries being breached or at risk of being breached $[2,3]$. These trends are due to a combination of growing population and increasing levels of resource consumption and waste generation. Against such well understood problems, it is becoming increasingly recognised that we require a tangible, quantitative vision of what a future sustainable and desirable world might look like [4].

The concept of the "ecological footprint" (EF) was first described by Rees [5] and later Wackernagel and Rees [6] and Rees [7] and is used to relate human consumption to carrying capacity via a common, and easily understood, unit of land area. Since its inception the EF has been used in many studies at 
global, national and sub-national levels. A database of national $E F$ accounts covering most countries in the world is maintained and updated by the Global Footprint Network (www.footprintnetwork.org).

The original $E F$ was conceived as a tool to compare human demand for biocapacity (productive ecosystems) with available supply, either within a study country or globally. A population's $E F$ is based on consumption directly linked to the productivity of land and sea ecosystems, relating to food (crops and animal products, as well as fish), fibre and timber. Each type of consumption could be represented, via a global average yield factor, by an equivalent land area (the 'footprint', in average units known as 'global hectares') that would be required to produce the food, fibre or timber. Importantly, the footprint accounting includes an assessment of the 'biocapacity', i.e., the land area (in global hectares) available for crops, livestock grazing and so on. The $E F$ accounting method remains an effective means for broadly assessing and communicating concepts relating to the carrying capacity of humans, based on consumption patterns at the national and global level.

Significantly, the EF presented by Wackernagel and Rees [6] included an energy footprint by equating energy consumption to land area. For renewable sources of energy (solar, wind, biomass) the yield and the spatial footprint could be estimated as for other forms of land use. However, the vast majority of energy consumed globally is derived from fossil fuels, the extraction of which carries a negligible physical land footprint; hence in the energy footprint, the consumption is not directly linked to the yield of energy with a known land area requirement. Two main options have been presented for the calculation of an areal energy footprint from fossil fuels: (i) the hypothetical substitution of fossil fuel energy with an equivalent amount of biomass energy (area calculated based on biomass energy yields), and (ii) the area of forest that would be required to assimilate the carbon emissions from burning fossil fuel (area calculated from average carbon uptake rates). The latter has been adopted the most widely in $E F$ studies and is the form used today in the national accounts maintained by the Global Footprint Network.

As currently calculated based on carbon uptake equivalence, the global carbon footprint $(C F)$ is 1.69 global hectares per person, making up some $59 \%$ of the total $E F$. At the global level, the $C F$ is the only component of the $E F$ that can be assessed as beyond the per-capita biocapacity (see Table 1), as the carbon entering the atmosphere exceeds the uptake capacity and this difference is measurable. Other categories of land use may well be in overshoot especially at the local scale, e.g., due to soil degradation, overfishing, etc., but this is not specifically measurable via the EF spatial accounting method. Therefore, if the $E F$ is to be used to demonstrate the human population's overall environmental footprint relative to Earth's carrying capacity, it can be said that the energy footprint makes up a substantial fraction of the calculated overshoot.

The use of carbon uptake rates to derive an equivalent land area provides a method for estimating the sustainability—or lack thereof-of carbon emissions from burning fossil fuels. However, several problems may arise if the $C F$ assessment is taken as the principal measure of the sustainability of our energy supply. These problems are articulated briefly below. It must be noted that these are not criticisms of the $E F$ accounting method, but rather point to the need to assess energy sustainability more broadly than carbon uptake alone.

Firstly, present-day energy use is unsustainable for two reasons: (i) excessive carbon emissions and (ii) depletion of non-renewable resources. The carbon-based method of footprint estimation addresses the former but not the latter. Mohr et al. [8] comprehensively modelled plausible future pathways for fossil fuel production globally, under low and high resource scenarios, and concluded that a supply constraint-driven peak and decline in fossil energy is inevitable by — at the latest-the middle of the 21st century. This means that even if we were able to bring carbon emissions to within biocapacity (say, by widely adopting some future carbon capture and sequestration technology), our energy supply would not be sustainable. A future sustainable energy scenario must be one in which (i) net carbon emissions are reduced to a sustainable level—perhaps zero-and (ii) non-renewable fossil fuels are replaced by renewable energy resources. 
Secondly, by reducing all energy to a common unit of carbon emissions, the $C F$ method does not interrogate the different quality (i.e., usefulness to the economy) of different sources of energy. For example, in Australia, grid-supplied electricity has an average emissions factor of $253 \mathrm{kgCO}_{2}$-e/GJ while petrol/gasoline carries an emissions factor of $67.4 \mathrm{kgCO}_{2}-\mathrm{e} / \mathrm{GJ}$ [9]. This means that for the same amount of land to assimilate carbon emissions, $1 \mathrm{GJ}$ of electricity would be equivalent $3.75 \mathrm{GJ}$ of petrol or gasoline. Moreover, these types of energy perform very different functions; notably, certain modes of transport (especially aviation and long-distance freight) are not currently, nor foreseeably likely to become, amenable to electric propulsion.

Thirdly, when only the $C F$ is counted towards the 'Energy' category of the $E F$, any land footprint associated with physical energy infrastructure would typically be counted via the 'Built up land' category. The spatial footprint associated with expanding renewable energy infrastructure- to reduce the $C F$-is relevant to policymakers, and to anyone concerned about whether future energy scenarios could physically fit within the carrying capacity of our planet. Indeed, as Scheidel and Sorman [10] point out, the low power density of renewable energy sources is likely to result in vast amounts of land being required to generate power. Irrespective of the $E F$ category to which such a footprint is ultimately added (energy vs. built up land), if we wish to envisage a hypothetical future scenario powered by $100 \%$ renewable energy, then a calculation procedure is required to determine the associated land requirements beyond carbon uptake from emissions.

Table 1. Global average ecological footprint, from the Global Footprint Network's 2016 National Footprint and Biocapacity Accounts [11].

\begin{tabular}{ccc}
\hline & Footprint (gha/person) & Biocapacity (gha/person) \\
\hline Cropland & 0.56 & 0.56 \\
Grazing & 0.16 & 0.21 \\
Forest Products & 0.27 & 0.73 \\
Carbon & 1.69 & - \\
Fish & 0.09 & 0.15 \\
Built up land & 0.06 & 0.06 \\
Total & 2.84 & 1.73 \\
\hline
\end{tabular}

The purpose of this paper is to demonstrate an approach to calculating a hypothetical energy footprint that is based on equivalent renewable energy, for which we propose the term "Renewable Energy Equivalent Footprint" (REEF). Rather than depicting the footprint of the current energy paradigm based on land uptake from unsustainable carbon emissions, the REEF calculates the hypothetical footprint of a future paradigm in which the electricity and fuel demands of today are met entirely by renewable energy. The REEF is an attempt to deliver a transparent, straightforward alternative to the $C F$, enabling the potential sustainability of energy consumption to be directly evaluated alongside other measures of $E F$ in the context of human carrying capacity.

In this paper, an approach is presented that is deliberately parsimonious, and is intended to be simple, transparent and repeatable rather than computationally complex and heavily data dependent. Importantly, our analysis considers electricity and fuel-based energy separately. This is significant as the net energy yield, as well as the input energy profile, can be very different for electricity and fuel-based renewable energy. Considering different types of energy allows a fuller picture of the relationship between overall energy and the land footprint.

The REEF is intended to be used either in place of, or-perhaps more likely-in conjunction with, the conventional $C F$ for global, national and local EF accounting. The method as described in this paper can also be applied to determine an equivalent land area that would be required to (renewably) support individual energy-consuming activities, to contextualise and communicate the impact of behaviour and consumption patterns in ways that relate more directly to carrying capacity. 


\section{Materials and Methods}

In order to link energy consumption with land area demand, we adopt a simplified energy supply model, dividing energy consumption into two types: electricity and non-electricity (i.e., broadly "fuels"). It is important to differentiate between electricity and fuels, because there are very different physical production systems involved with very different power density (the average rate of energy produced over time per unit area), and different behaviour in terms of input energy that must be invested in the renewable energy production system.

Although it is easy to conceive of a far more complex energy model (e.g., one considering solid, liquid and gaseous renewable fuels, as well as different sources of renewable electricity such as solar, wind, hydro, geothermal etc.), for the purposes of demonstrating an easily replicable model and drawing broad conclusions related to carrying capacity, we contend it is not necessary to segregate further than electricity and non-electricity. Moreover, as we are simulating a hypothetical, long-term future scenario of $100 \%$ renewable energy, it would be inappropriate and potentially misleading to assume too much detail about the make-up of the future energy system.

All renewable energy systems — with the exception of geothermal—can be considered to be solar energy, with different technologies capable of harvesting and converting different proportions of overall incoming solar power into forms useful for humans (electricity or biomass). Scheidel and Sorman [10] reviewed the yields of numerous renewable power systems in the context of a possible future "land $\mathrm{grab}^{\prime \prime}$ in the shift to renewable energy, and showed a tenfold (or more) difference in power density between the lowest (biomass: $0-0.6$ with average $0.5 \mathrm{~W} / \mathrm{m}^{2}$ ) and highest (concentrating solar thermal: $\left.4-10 \mathrm{~W} / \mathrm{m}^{2}\right)$.

Following the conventional EF calculation procedure [12], the gross energy production ( $E_{\text {gross }}$ for electricity and $F_{\text {gross }}$ for fuel) is related to an approximate (global average) production area by dividing by the average yield:

$$
\begin{aligned}
& A_{\text {elec }}=\frac{E_{\text {gross }}}{Y_{\text {elec }}} \times E Q F \\
& A_{\text {fuel }}=\frac{F_{\text {gross }}}{Y_{\text {fuel }}} \times E Q F
\end{aligned}
$$

where $Y_{\text {elec }}$ and $Y_{\text {fuel }}$ are the global average yields for electricity and biofuel, respectively (units are energy per unit area per time, e.g., GJ/ha/y). The term $E Q F$ is an 'equivalence factor', representing the productivity of the biocapacity category relative to average biological productivity [12]. For simplicity, in this study we will assume $E Q F=1.28$, corresponding to the value used for both carbon footprint and forest biocapacity in current $E F$ assessments [11], enabling the calculated energy production areas to be compared with forest biocapacity. It is possible to imagine energy production taking place in other land categories (e.g., grazing land), in which case the analysis could be repeated using a different value of $E Q F$.

The renewable energy equivalent footprint (REEF) is simply the sum of the two energy production areas, plus the non-energy component of the original carbon footprint:

$$
R E E F=A_{\text {elec }}+A_{\text {fuel }}+\left(1-\frac{C_{\text {energy }}}{C_{\text {total }}}\right) C F
$$

where $C_{\text {energy }}$ and $C_{\text {total }}$ are the energy-related and total carbon emissions used in the original carbon footprint calculation, respectively, and $C F$ is the area of the original carbon footprint. This formulation allows the REEF to account for carbon emissions from non-energy activities such as agriculture and cement production.

In addition to the areal power density, we must consider the fact that renewable energy technologies—as with all energy supplies-require input energy (beyond the solar radiation they are harvesting). To be of use to human activity, energy supplies must yield a net or surplus above the energy invested in their generation. This is termed the "energy return on energy invested", or EROI. 
Various energy supply technologies—-both non-renewable and renewable-have been reviewed in the literature [13-15]. EROI values reported in the literature are highly variable, as different calculation methods yield different net energy depending on the placement of the boundary for inputs versus outputs. However, the consensus is that as the overall EROI decreases (e.g., if energy becomes harder to obtain), the energy source becomes less useful, and an energy supply with EROI at or below 1 tends to be viewed as useless as there is no net energy available to use; Hall et al. [15] proposed a minimum EROI of 3 for energy to be useful to society. Moriarty and Honnery [16] claim that the low EROI of renewable energy technologies relative to fossil fuels imposes a significant limit to their usefulness. However, we contend that when multiple energy types are included in the supply model (even as few as two, as in ours), it is possible to envisage a scenario of cross-subsidisation where high-EROI forms of energy can provide input for low-EROI forms of energy. In such a system, the production of highly energy-dense, but low-EROI, liquid fuels derived from biomass may plausibly be subsidised by more efficient (high-EROI) solar electricity. As long as the system obtains a satisfactory net energy yield overall, and a sufficient fraction of the energy re-invested in the low-EROI production component can be met using high-EROI energy, it may be possible to envisage a basically functional energy supply.

In our simplified energy supply model, both types of renewable energy are assumed to receive inputs from both types of energy, i.e., electricity is invested in both electricity and biomass production, and likewise biomass energy is invested in both biomass and electricity production, in relatively predictable proportions. Figure 1 shows the simplified energy supply model with cross-subsidisation of energy sources and net energy flows to society.

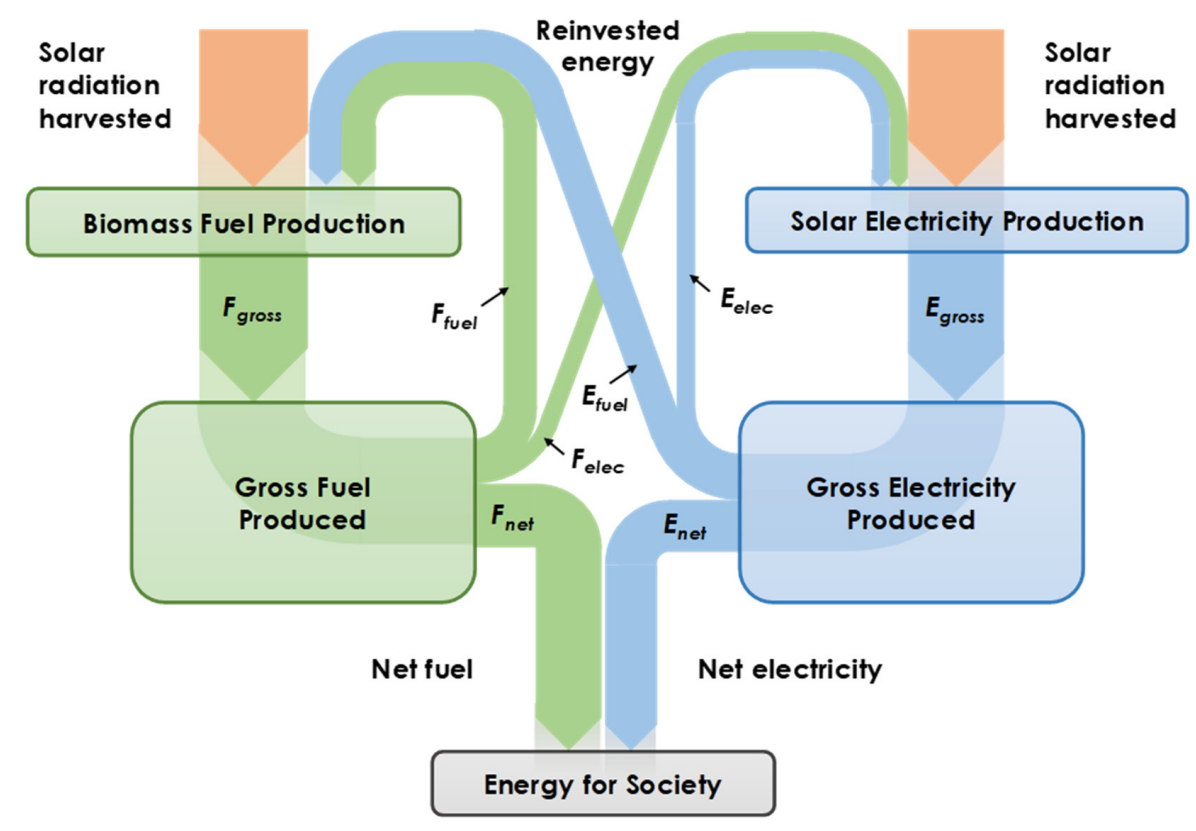

Figure 1. Conceptual model of simplified two-mode energy supply with electricity and bioenergy, including reinvestment of both forms of energy in each other. Arrow widths are indicative only (not to scale).

The calculation procedure begins with the assumption that net electricity $\left(E_{n e t}\right)$ and fuel $\left(F_{n e t}\right)$ demands are known, or can be reliably estimated. These could be the per capita energy demands at a national level, or the demand from a specific activity. Assuming conservation of energy, for electricity we then have:

$$
E_{\text {gross }}-E_{\text {elec }}-E_{\text {fuel }}=E_{\text {net }}
$$

where $E_{\text {elec }}$ is the electrical energy reinvested in the electricity production system, and $E_{f u e l}$ is the electrical energy reinvested in the biofuel production system. Units for all terms in Equation (4) are energy per time (e.g., PJ/y). 
Likewise, for fuel, we have:

$$
F_{\text {gross }}-F_{\text {elec }}-F_{\text {fuel }}=F_{\text {net }}
$$

where $F$ denotes fuel energy and subscripts are as per Equation (4).

The model must account for reinvestment of energy in the energy supply, so we can relate the gross output of energy to the input energy via the energy return on energy invested (EROI, dimensionless) for each fuel type:

$$
\begin{aligned}
E^{2} O I_{\text {elec }} & =\frac{E_{\text {gross }}}{E_{\text {elec }}+F_{\text {elec }}} \\
E R O I_{\text {fuel }} & =\frac{F_{\text {gross }}}{E_{\text {fuel }}+F_{\text {fuel }}}
\end{aligned}
$$

Finally, we define a fuel-electricity input ratio ( $F E$, dimensionless) for the energy invested:

$$
\begin{gathered}
F E_{\text {fuel }}=\frac{F_{\text {fuel }}}{E_{\text {fuel }}} \\
F E_{\text {elec }}=\frac{F_{\text {elec }}}{E_{\text {elec }}}
\end{gathered}
$$

It is assumed that the following parameters are known, or can be reliably estimated: net energy requirements $\left(E_{\text {net }}\right.$ and $\left.F_{\text {net }}\right)$ for a given nation or process under consideration; energy return on energy invested for each energy production system $\left(E R O I_{\text {elec }}\right.$ and $\left.E R O I_{f u e l}\right)$; and the fuel-electricity input ratio for each energy production system $\left(F E_{\text {fuel }}\right.$ and $\left.F E_{\text {elec }}\right)$. This leaves six unknown variables $\left(E_{\text {gross }}, E_{\text {elec, }}\right.$, $E_{\text {fuel }}, F_{\text {gross }}, F_{\text {elec }}$ and $F_{\text {fuel }}$ ) which can be solved using the six simultaneous equations (Equations (4)-(9)). A solution procedure is given in Appendix A.

The REEF can be calculated for a given energy-consuming activity, or for the overall energy needs of a community, a nation or the world.

To calculate the REEF required to support a specific energy-consuming activity, we first require the energy consumption rate $\left(F_{n e t}\right.$ and $\left.E_{n e t}\right)$. Then the EROI and FE terms must be obtained for both energy production processes. Note that even if evaluating the REEF for a single type of energy (e.g., transport fuel demand where $E_{n e t}=0$ ), the remaining terms are still required for both types of energy to evaluate the whole input to the energy production system. For example, demand for renewable transport fuel for a specific transport activity will require land for the biofuel production, plus the land for extra fuel to be reinvested in the production process, as well as additional land for solar electricity to supply the electrical demands of the biofuel production process, even if no electricity is consumed in the final activity.

To calculate the REEF at the community, national or global level, we need net energy use separated into fuel and electricity. In the following section we will present the results of the REEF calculated for 127 countries. We assume final energy demand is a satisfactory proxy for net energy $\left(E_{n e t}, F_{n e t}\right)$ used in the REEF model. For this analysis, data for final energy demand (total, electricity, and later, transport) for 2014 were purchased from the International Energy Agency (https://www.iea.org/data-and-statistics).

\section{Results}

\subsection{Uncertainty and Sensitivity Analysis}

Given that uncertainty exists in Y, EROI and FE for both fuel and electricity, it is appropriate to conduct a sensitivity analysis. To do this, parameters are varied (one at a time) over the range specified in Table 2, while all other parameters are fixed at the base case value. The net energy demands ( $E_{n e t}$ and $\left.F_{n e t}\right)$ are somewhat arbitrary in the sensitivity analysis; in this case we select the per capita demands for Australia so as to provide results in the context of a high-Human Development Index (HDI) country. Australia has one of the highest Human Development Index values in the world (HDI $=0.93$ ), and both 
high per capita income and high energy demand in global terms. For the base case, the ratio of fuel and electrical input energy into each energy type (i.e., $F E_{f u e l}$ and $F E_{\text {elec }}$ ) is assumed to mirror the ratio of fuel and electricity in the overall energy system, such that $F E_{\text {fuel }}=F E_{\text {elec }}=F_{\text {net }} / E_{\text {net }}$.

Table 2. Base case values and range for sensitivity analysis.

\begin{tabular}{ccccc}
\hline Parameter & Units & Base Case Value & Min & Max \\
\hline $\boldsymbol{E}_{\text {net }}$ & GJ/y per capita & 32.5 & - & - \\
$\boldsymbol{F}_{\text {net }}$ & GJ/y per capita & 115 & - & - \\
RROI $_{\text {fuel }}$ & $(-)$ & 2 & 0.5 & 20 \\
$\boldsymbol{E R O I}_{\text {elec }}$ & $(-)$ & 12 & 0.5 & 20 \\
$\boldsymbol{Y}_{\text {fuel }}$ & $\mathrm{W} / \mathrm{m}^{2}$ & 0.5 & 0.3 & 3 \\
$\boldsymbol{Y}_{\text {elec }}$ & $\mathrm{W} / \mathrm{m}^{2}$ & 6 & 4 & 9 \\
$\boldsymbol{F} \boldsymbol{E}_{\text {fuel }}$ & $(-)$ & 3.53 & $0.001^{\mathrm{a}}$ & $1000^{\mathrm{a}}$ \\
$\boldsymbol{F} \boldsymbol{E}_{\text {elec }}$ & $(-)$ & 3.53 & $0.001^{\mathrm{a}}$ & $1000^{\mathrm{a}}$ \\
\hline
\end{tabular}

Figure 2 shows the variation in $A_{f u e l}$ and $A_{\text {elec }}$ over the range for each parameter. $A_{\text {elec }}$ is always much smaller than $A_{\text {fuel }}$ for three reasons: firstly, the yield $Y_{\text {elec }}$ is larger than $Y_{\text {fuel }}$; secondly, the electricity demand is considerably smaller than the fuel demand; and thirdly, EROI elec is greater than $E R O I_{\text {fuel }}$.

Sensitivity of $A_{\text {fuel }}$ and $A_{\text {elec }}$ to inputs

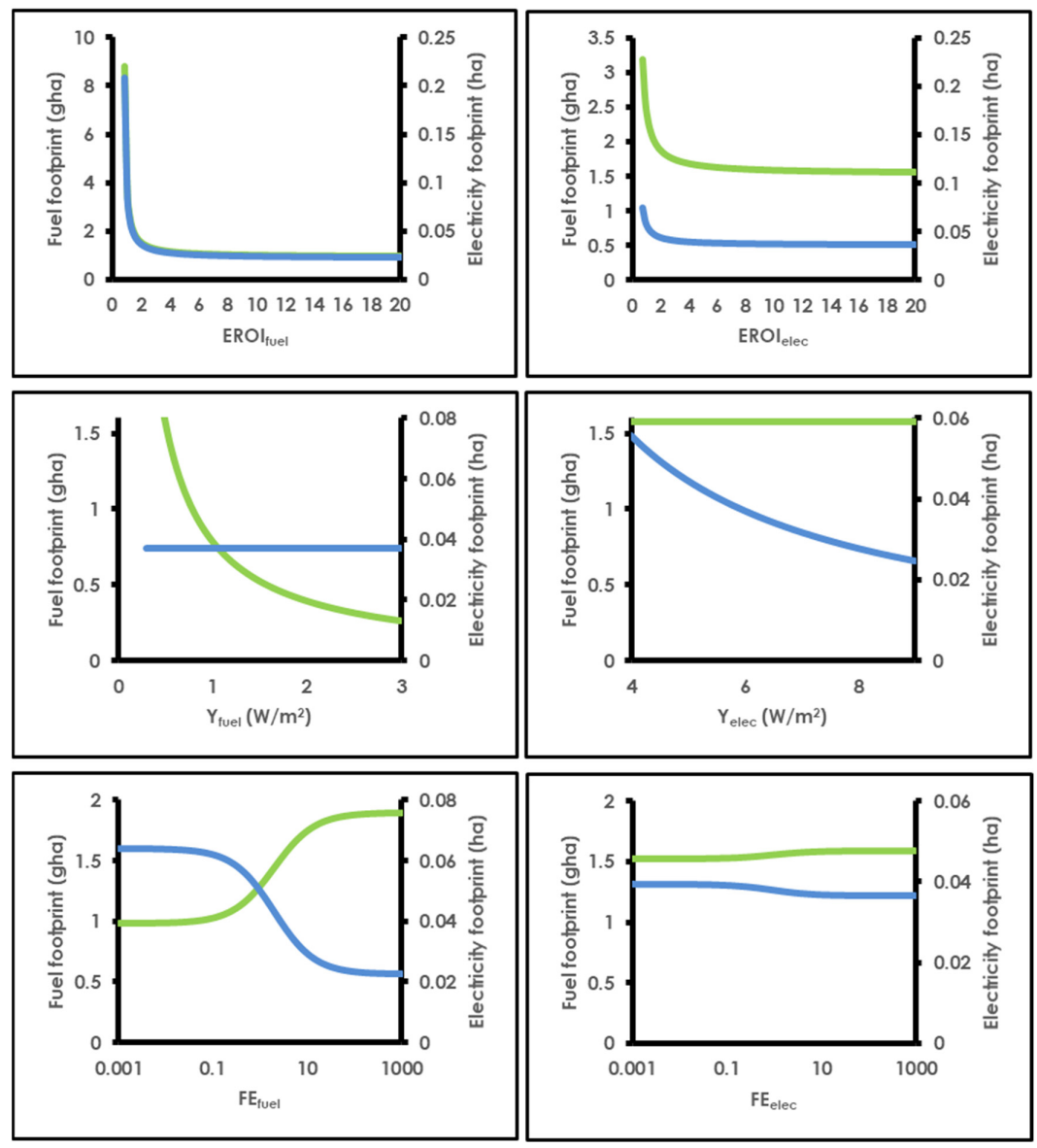

Fuel Electricity

Figure 2. Sensitivity analysis results, reported as per capita fuel and electricity footprints for average Australian energy consumption. 
Sensitivity to EROI shows that when varying this parameter for either fuel or electricity, both footprints respond as a result. Both footprints are relatively constant above approximately $E R O I=3$ (for either energy type), and both footprints rise steeply when either $E R O I<2$. This is consistent with the findings of Hall [15] who determined a practical lower limit for an energy source (for it to be useful to society) at around $E R O I=3$.

Varying yield only affects the footprint of the corresponding energy type. This reflects the assumptions in the calculation procedure, where EROI is held constant, i.e., the same amount of energy is invested in the production of energy, irrespective of the yield. It is possible to envisage scenarios in which an increase in yield is accompanied by either an increase in EROI (e.g., if energy inputs scaled predominantly with area), or a decrease in EROI (e.g., if energy inputs scaled largely with power density). In light of such uncertainty, taking a constant EROI with respect to yield is considered to provide a reasonable approximation.

The effect of varying the ratio of fuel to electricity in the inputs is different for each energy source due to the differences in baseline EROI. For fuel, the low baseline EROI means that $A_{\text {fuel }}$ and $A_{\text {elec }}$ are strongly influenced by whether the inputs are fuel-dominated $\left(F E_{f u e l}>>1\right)$ versus electricity-dominated $\left(F E_{f u e l}<<1\right)$. As fuel represents three quarters of the total net energy in the test scenario, the overall electricity footprint is strongly influenced by the amount of electricity that must be generated as input to the fuel production. In contrast, electricity has a relatively high baseline EROI and represents a much smaller proportion of the overall energy use, hence varying $F E_{\text {elec }}$ has minimal impact on the two energy footprints.

The analysis reveals substantial differences in both the overall calculated footprint and the sensitivity to inputs for the fuel and electricity fractions of the $R E E F$, suggesting that the distribution of energy demand (electricity versus fuel) will significantly impact the overall REEF. According to the data from the IEA, the fraction of electricity in Final Energy Demand varies over a wide range, from less than 2\% (Tanzania, Nigeria, Ethiopia and Haiti) to over 30\% (Tajikistan, Bahrain, Montenegro, Sweden, Macedonia, Israel and Kyrgyzstan). Figure 3 shows that the degree of electrification (as a percentage of Final Energy Demand) tends to be lowest for the lowest-HDI countries but that there is large variability in electrification especially among medium- and high-HDI countries.

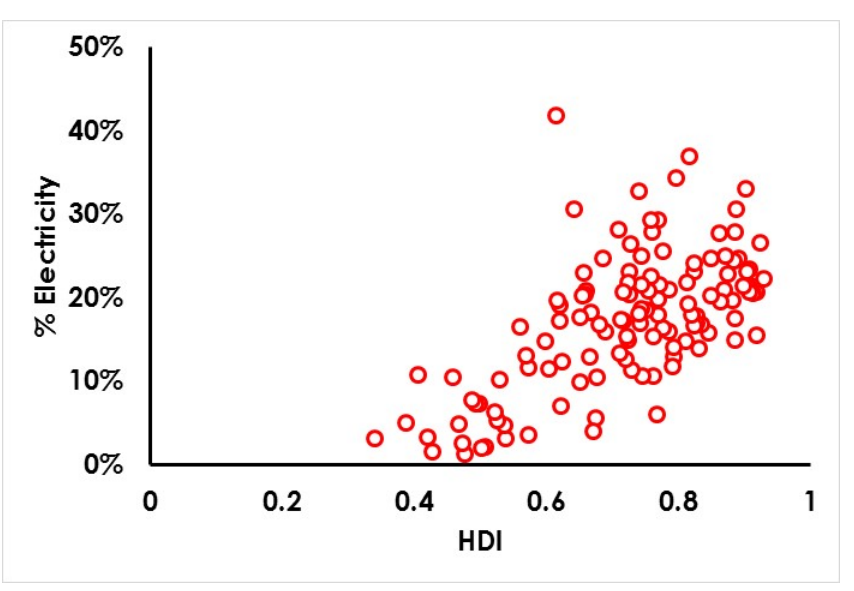

Figure 3. Degree of electrification versus Human Development Index.

In light of the variability in electrification and its likely influence on the $R E E F$, a further sensitivity analysis was conducted as shown in Figure 4, again using Australia's per capita energy consumption as a base case (for reference, Australia's Final Energy Demand is currently 22\% electricity). Keeping total energy demand constant, the proportion coming from electricity was varied over a hypothetical range from 1-99\%. From this simple analysis it is clear that the combination of low yield and low EROI of biomass causes the fuel footprint to dominate the REEF; even at $80 \%$ electrification, fuel production 
still accounts for $75 \%$ of the overall energy footprint. The electricity footprint only exceeds the fuel footprint once electrification exceeds $93 \%$.

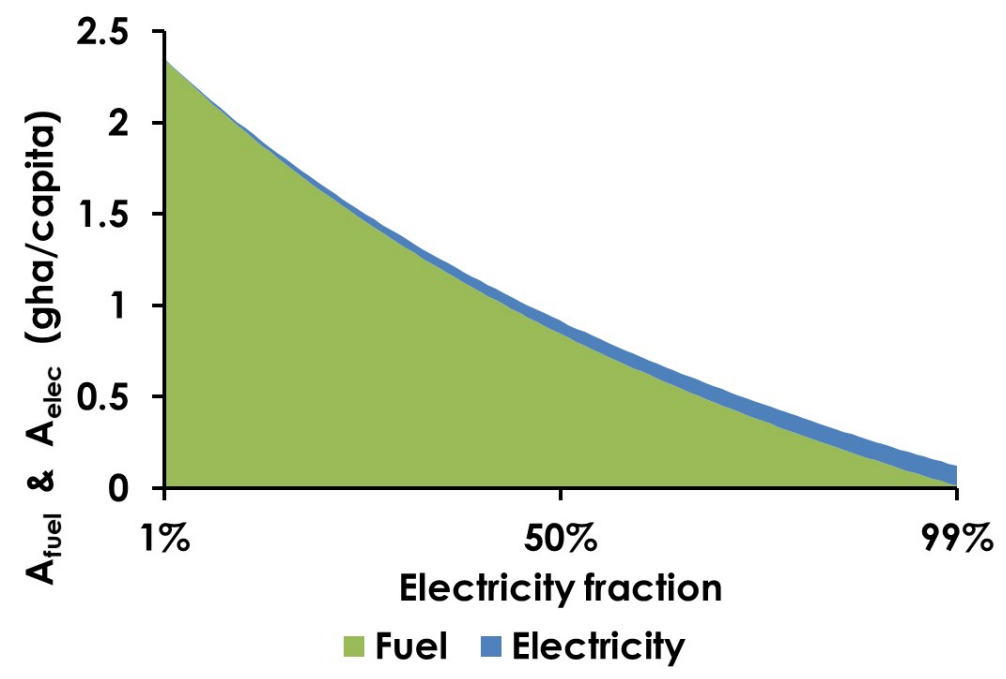

Figure 4. Sensitivity and breakdown (fuel/electricity) of per cCapita "Renewable Energy Equivalent Footprint" (REEF) to fraction of electricity in Final Energy Demand, based on Australian energy demand.

\subsection{Carbon Footprint vs. REEF for Nations}

The REEF is calculated for 127 nations, using IEA data for Final Energy Demand. $E_{n e t}$ is taken as current demand for electricity, while $F_{\text {net }}$ is assumed to be all remaining non-electric energy. Values used for $Y$ and EROI for each energy type are taken as the base case values from Table 2. FE is assumed to be the same for both fuels and is taken as the ratio of $F_{\text {net }}$ to $E_{\text {net }}$, per the sensitivity analysis. Energy-related carbon emissions $\left(C_{\text {energy }}\right)$ for each country are estimated from World Resources Institute database of emissions ( $\mathrm{CO}_{2}$-equivalent) by sector, and are taken as the sum of "energy" and "bunker fuels". Total carbon emissions $\left(C_{\text {total }}\right)$ are the total emissions from all sectors in the database.

The ratio of the $R E E F$ to the original $C F$ is found to depend on the degree of electrification-countries with very little $(<10 \%)$ electricity may have a $R E E F$ substantially greater than $C F$, while most countries with $>20 \%$ electricity have REEF approximately half of the $C F$ (Figure 5).

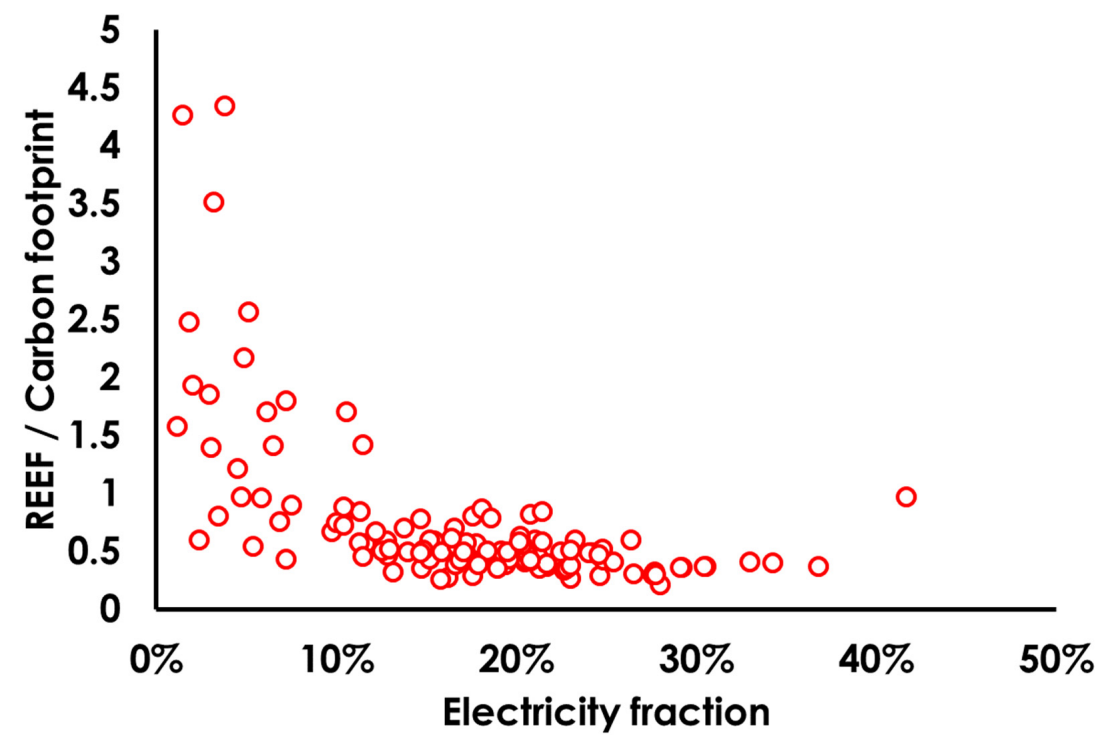

Figure 5. Ratio of REEF to carbon footprint versus fraction of electricity in Final Energy Demand. 
Figure 6 presents selected national results for the REEF compared to the original $C F$. For high and middle carbon emissions countries, the REEF is approximately $50 \%$ and $53 \%$ of $C F$, respectively. This reduction is partly due to the substantial degree of electrification in these countries (allowing a greater fraction of the hypothetical renewable energy to be provided by the higher-yielding solar electricity). The lowest carbon emissions countries have the lowest degree of electrification, coupled with a somewhat low energy fraction of total carbon emissions, resulting in high biofuel and non-energy carbon fractions in the derived REEF. The result, for these countries, is a total REEF that is approximately double the $C F$ (average 220\% for the ten lowest emitting countries).
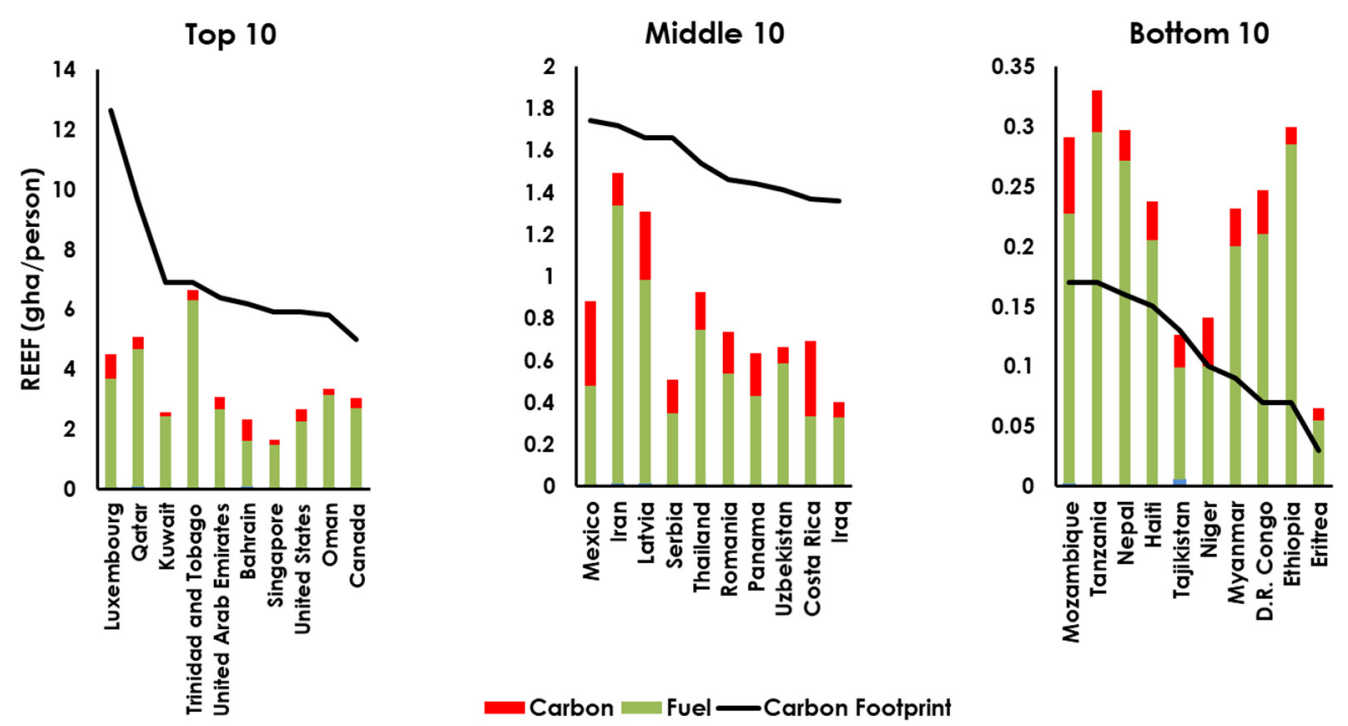

Figure 6. Comparison of REEF and carbon footprints for top 10, middle 10 and bottom 10 countries (ordered by carbon footprint).

On average, replacing the $C F$ with the $R E E F$ results in energy representing just over one third of total $E F$ (mean $37 \%$, median $35 \%$ ). Using the original $C F$ value, energy represents on average about half of the total $E F$ (mean $50 \%$, median $54 \%$ ), and for a substantial number of countries the carbon footprint is more than $60 \%$ of the total $E F$. Using the REEF, two-thirds $(65 \%)$ of countries have an energy footprint that makes up less than $40 \%$ of the total $E F$. As Figure 7 shows, the REEF is both substantially smaller on average and less variable than the carbon footprint.

Out of 127 sampled countries, under the conventional carbon footprint accounting, the number of countries in "ecological surplus" (i.e., total biocapacity greater than total $E F)$ is $30(24 \%)$. This increases to 43 (34\%) using the REEF. Globally, the population-weighted average $E F$ declines from 2.9 gha/person (using carbon footprint) to $2.0 \mathrm{gha} /$ person (using REEF). The latter is approaching the global biocapacity of $1.8 \mathrm{gha} /$ person.

One important aspect of the REEF is that it allows the disaggregation of area required for the two different energy types and assimilation of non-energy carbon emissions. Globally, the biomass component $\left(A_{\text {fuel }}\right)$ is some fifty times larger than the electricity component $\left(A_{\text {elec }}\right)$, and the total REEF comprises approximately one-quarter carbon (the non-energy fraction of carbon emissions) and three-quarters energy production area. 


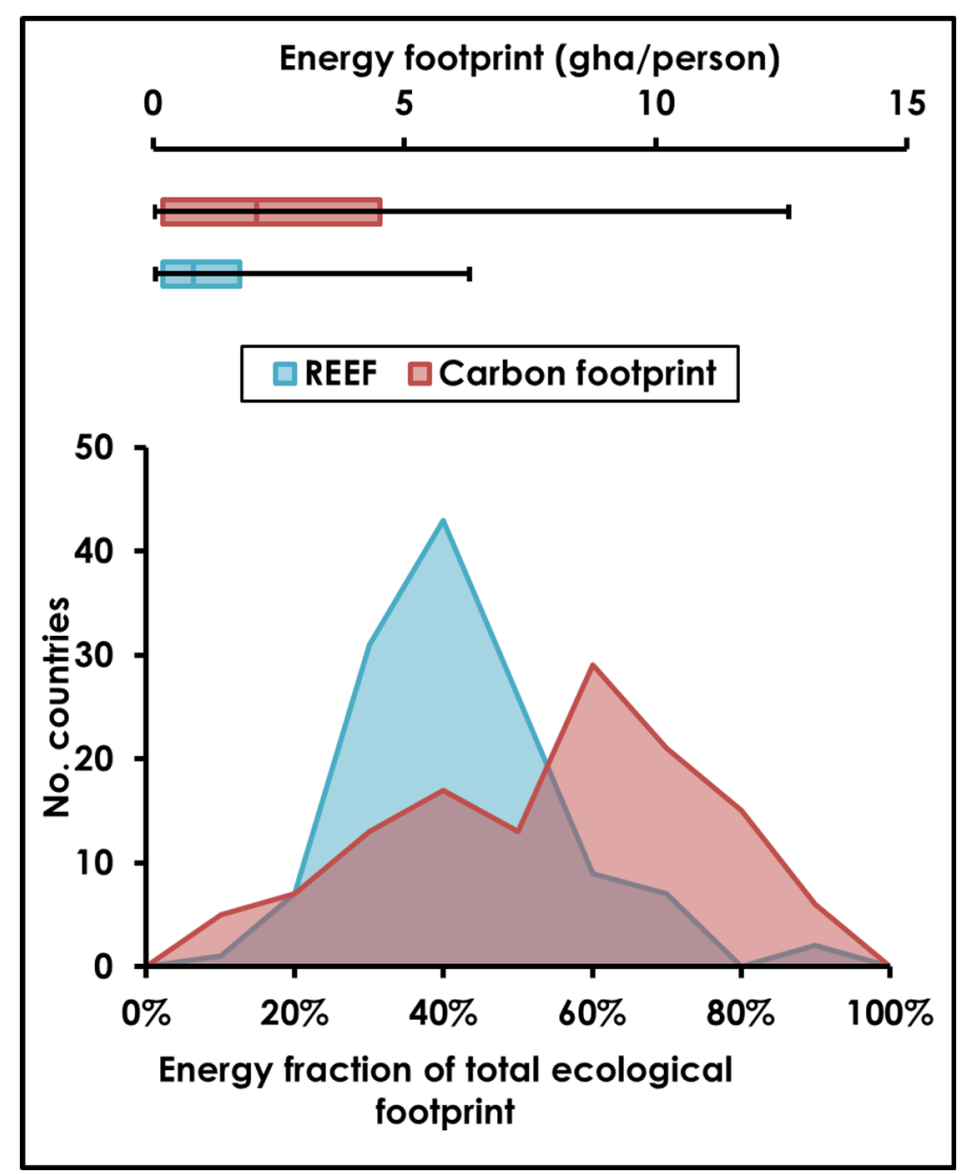

Figure 7. Range of REEF and carbon footprints, and distribution of energy as a fraction of total ecological footprint by country. For the footprint size, the boxplot shows 10th and 90th percentiles, with a mid-line at the (unweighted) mean across countries and error bars extending to the minimum and maximum.

\subsection{Envisioning a Sustainable Energy Future}

The REEF has shown that current human energy demands, if met by renewable energy using conventional biomass and electricity sources, could potentially require a land footprint greater than all remaining forest biocapacity; in such a scenario nothing would be left for nature. In order to explore potential improvements to this situation, several hypothetical scenarios are tested, with parameters summarised in Table 3. In addition to the base case (Scenario 1), two technological advances are tested. Scenario 2 involves a radical electrification of the energy supply, assuming $75 \%$ of final energy demand for each country can be met with electricity. In this case the $25 \%$ non-electrified supply covers the fraction of energy demand that will remain too difficult or costly to electrify; it is currently impossible to predict the fraction of transport that may ultimately be electrified, and the fraction of other energy uses (such as high-temperature industrial heat) that may be able to be supplied directly or indirectly with electricity. Scenario 3 then explores a potential further reduction in fuel footprint by adopting technology in which electricity is used to convert atmospheric gases into fuel. The yield $\left(\mathrm{W} / \mathrm{m}^{2}\right)$ of such an industrial fuel production process would be inherently very high but in an attempt to avoid unhelpful technological optimism, a reduced EROI (0.5) is adopted for this synthetic fuel ('synfuel') in Scenario 3, i.e., assuming it takes two units of input energy to produce one unit of synfuel energy. 
Table 3. Scenario parameters.

\begin{tabular}{|c|c|c|}
\hline Scenario & Fraction Electricity vs. Fuel & Fuel Yield + EROI \\
\hline 1. Base Case & $\begin{aligned} E_{\text {net }}= & \text { final energy demand } \\
& \text { (electricity) } \\
F_{\text {net }}= & \text { final energy demand } \\
& \text { (non-electricity) }\end{aligned}$ & $\begin{array}{c}Y_{f u e l}=0.5 \mathrm{~W} / \mathrm{m}^{2} \\
\text { EROI }_{\text {fuel }}=2\end{array}$ \\
\hline 2. Electrification & $\begin{array}{l}F_{n e t}=25 \% \text { final energy demand } \\
E_{n e t}=75 \% \text { final energy demand }\end{array}$ & $\begin{array}{c}Y_{\text {fuel }}=0.5 \mathrm{~W} / \mathrm{m}^{2} \\
\text { EROI }_{\text {fuel }}=2\end{array}$ \\
\hline 3. Electricity + Synfuel & As per Scenario 2 & $\begin{array}{l}Y_{\text {fuel }}=100 \mathrm{~W} / \mathrm{m}^{2} \\
\text { EROI } \\
\text { fuel } \\
=0.5\end{array}$ \\
\hline
\end{tabular}

The results of the four scenarios are summarised in Table 4. In scenarios 2 and 3, the energy footprint is now dominated by the non-energy carbon assimilation component, with the renewable energy harvesting fraction $\left(A_{\text {fuel }}+A_{\text {elec }}\right)$ representing less than half of the REEF. The number of countries that would be domestically in surplus (i.e., overall biocapacity $>$ overall $E F$ ) would theoretically double from 30 to 61 when comparing the base case (Scenario 1) to the best case (Scenario 3). It is significant to note that despite the highly optimistic assumptions embedded in this scenario, the number of countries in outright surplus would still be less than half (61 out of 127 assessed).

Table 4. Energy footprint related to total and forest biocapacity.

\begin{tabular}{|c|c|c|c|c|}
\hline & $\begin{array}{l}\text { Carbon } \\
\text { Footprint }\end{array}$ & $\begin{array}{l}\text { Scenario 1: } \\
\text { Base Case }\end{array}$ & $\begin{array}{l}\text { Scenario 2: } \\
\text { Electrification }\end{array}$ & $\begin{array}{c}\text { Scenario 3: } \\
\text { Elec. }+ \\
\text { Synfuel }\end{array}$ \\
\hline \multicolumn{5}{|c|}{ Energy footprint (gha/person) } \\
\hline Carbon & \multicolumn{2}{|c|}{1.7} & \multicolumn{2}{|c|}{0.20} \\
\hline Electricity & - & 0.011 & 0.034 & 0.064 \\
\hline Fuel & - & 0.63 & 0.137 & 0.001 \\
\hline Total & 1.7 & 0.64 & 0.17 & 0.06 \\
\hline Total $E F$ & 2.9 & 2.0 & 1.5 & 1.4 \\
\hline $\begin{array}{l}\text { No. countries } \\
\text { in surplus } \\
\text { (total } E F \text { vs. } \\
\text { total } \\
\text { biocapacity a) }\end{array}$ & 30 & 43 & 57 & 61 \\
\hline \multicolumn{5}{|c|}{ Appropriation of spare forest biocapacity ${ }^{b}$} \\
\hline Carbon & \multicolumn{2}{|c|}{$371 \%$} & \multicolumn{2}{|c|}{$43 \%$} \\
\hline Electricity & - & $2.6 \%$ & $7 \%$ & $14 \%$ \\
\hline Fuel & - & $136 \%$ & $30 \%$ & $0.3 \%$ \\
\hline
\end{tabular}

a Based on domestic biocapacity of each country. ${ }^{b}$ Population-weighted means across countries to provide global average.

Table 4 includes an estimate of the appropriation of spare forest biocapacity, assuming forests are the main source of "spare" biocapacity available to assimilate non-energy carbon emissions as well as provide the land needed for renewable energy production. However, it is possible to imagine some or perhaps even all of the electricity generating area $\left(A_{\text {elec }}\right)$ being met using a combination of non-productive land (e.g., desert solar farms), offshore wind, onshore wind that shares land with other uses such as grazing and cropping, as well as rooftop solar that shares its areal footprint with the existing built environment. However, it is instructive to use forest biocapacity to provide an indication of the scale that would be required: even the best case scenario requires productive area equivalent to roughly one-seventh of the world's spare forest. (Note that here "spare" forest biocapacity is taken as the global average forest biocapacity minus the global average forest products consumption footprint.)

In the base case, we see that the world is well over capacity: $43 \%$ of the currently unused forest is already required to be left aside for assimilation of non-energy carbon emissions, and then a further 
$136 \%$ would be required for biofuel production-i.e., an impossible scenario. In the $75 \%$ electrification scenario (Scenario 2), approximately $80 \%$ of forest capacity is required, with almost one-third needing to be converted into biofuel production. In the highly optimistic synfuel scenario (Scenario 3), the fuel comes with an almost negligible footprint due to its high assumed yield, but its low EROI results in a doubling of electricity footprint from Scenario 2, requiring the equivalent of $14 \%$ of forest biocapacity. In this case the appropriation of forest biocapacity would drop to $57 \%$, of which $43 \%$ is the area required for assimilation of non-energy carbon emissions.

While the results in Table 4 are instructive in terms of describing global carrying capacity based on average global energy consumption, and the impact of possible technological development, they do not greatly assist us in the exposition of local consumption patterns that are both globally sustainable and desirable, which are needed to guide policy and behaviour change. To do this, we conduct a nation-by-nation analysis that considers both energy consumption (sustainability) and HDI (desirability).

Figure 8 presents the results of all three scenarios, with each nation mapped according to its original carbon footprint and REEF, as well as HDI. The vertical axis on the graph represents the appropriation of spare biocapacity; for the original $C F$ this is the required area as a fraction of global average forest biocapacity minus domestic forest product footprint. For the REEF, it is a fraction of global average forest biocapacity minus both the domestic forest footprint and the non-energy carbon footprint. In other words, it represents energy-producing land area as a fraction of a globally equitable share of the world's forest, once the nation's consumption of other forest products and carbon assimilation requirements have been accounted for. This measure thus represents the extent to which the local energy consumption patterns of each nation could be sustainably replicated worldwide.

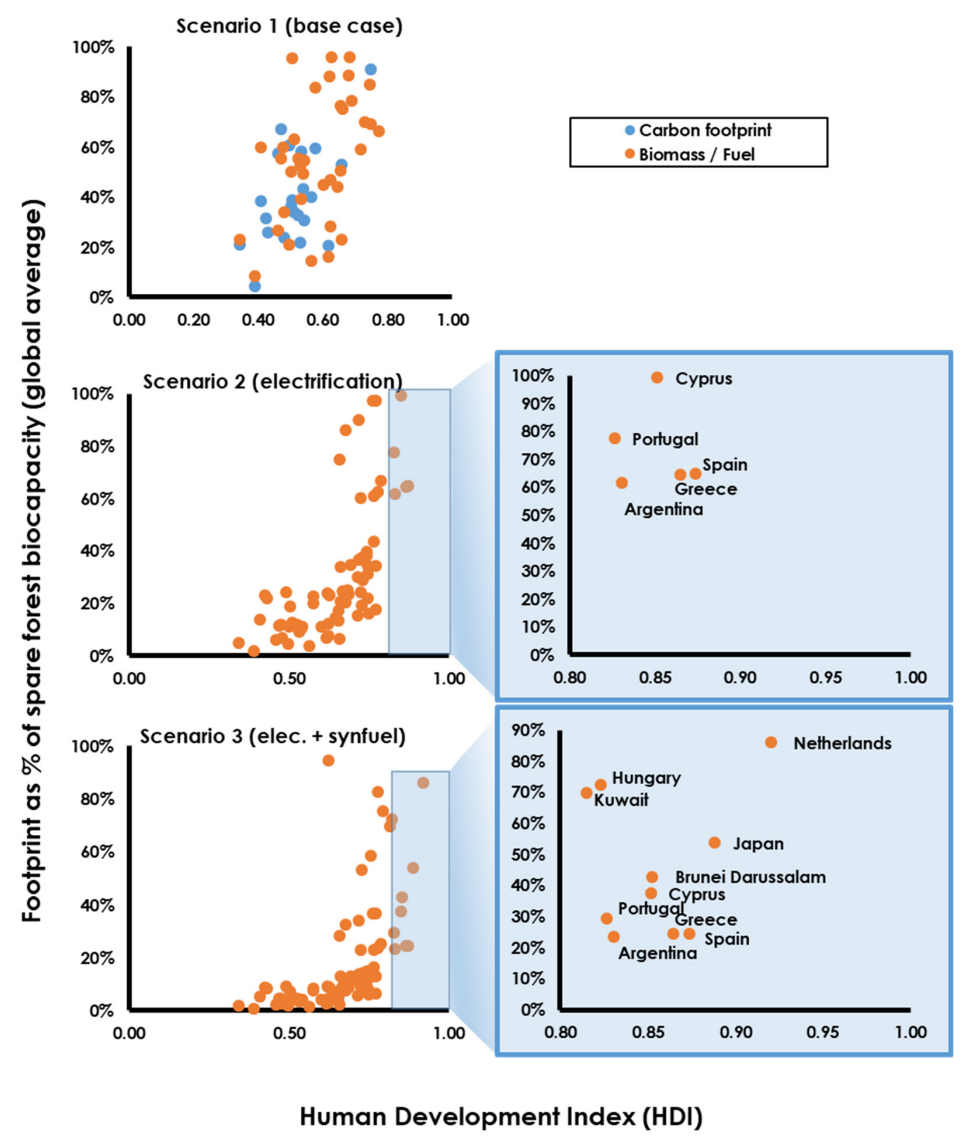

Figure 8. Required appropriation of forest area (based on a global average) for energy and carbon versus Human Development Index for countries. 
We consider a satisfactorily high HDI threshold level as 0.8, following Moran et al. [17]. In both the original CF and the base case REEF scenario, there are no nations with HDI $>0.8$ and an energy footprint that can be met with a globally equitable share of forest biocapacity. In Scenario 2, a collective of five high-HDI countries (Argentina, Cyprus, Greece, Portugal and Spain) appear, and in the highly optimistic Scenario 3 another five countries (Brunei Darussalam, Hungary, Japan, Kuwait and the Netherlands) are identified.

The culturally and geographically diverse group of countries identified in Scenario 3 can be used as exemplars whose combination of energy and non-energy carbon emissions could potentially represent a globally equitable consumption level, albeit being dependent on very substantial technological development (namely radical electrification of the energy mix coupled with massive deployment of synthetic fuels). Figure 9 provides the breakdown of each country's appropriation of forest biocapacity, based on a globally equitable share, according to consumption type. This includes the hypothetical area $A_{\text {fuel }}+A_{\text {elec }}$ from the best-case (Scenario 3), as well as the area required for assimilation of non-energy carbon emissions, and forest products [11]. In most cases, the area required for assimilation of non-energy carbon emissions is substantial, but it should be noted that this implies passive use of forest area that need not compete with natural ecosystems. Active uses of the forest area (i.e., competing with natural ecosystems) are the production of renewable energy and the-generally larger-area required for provision of existing forest products.

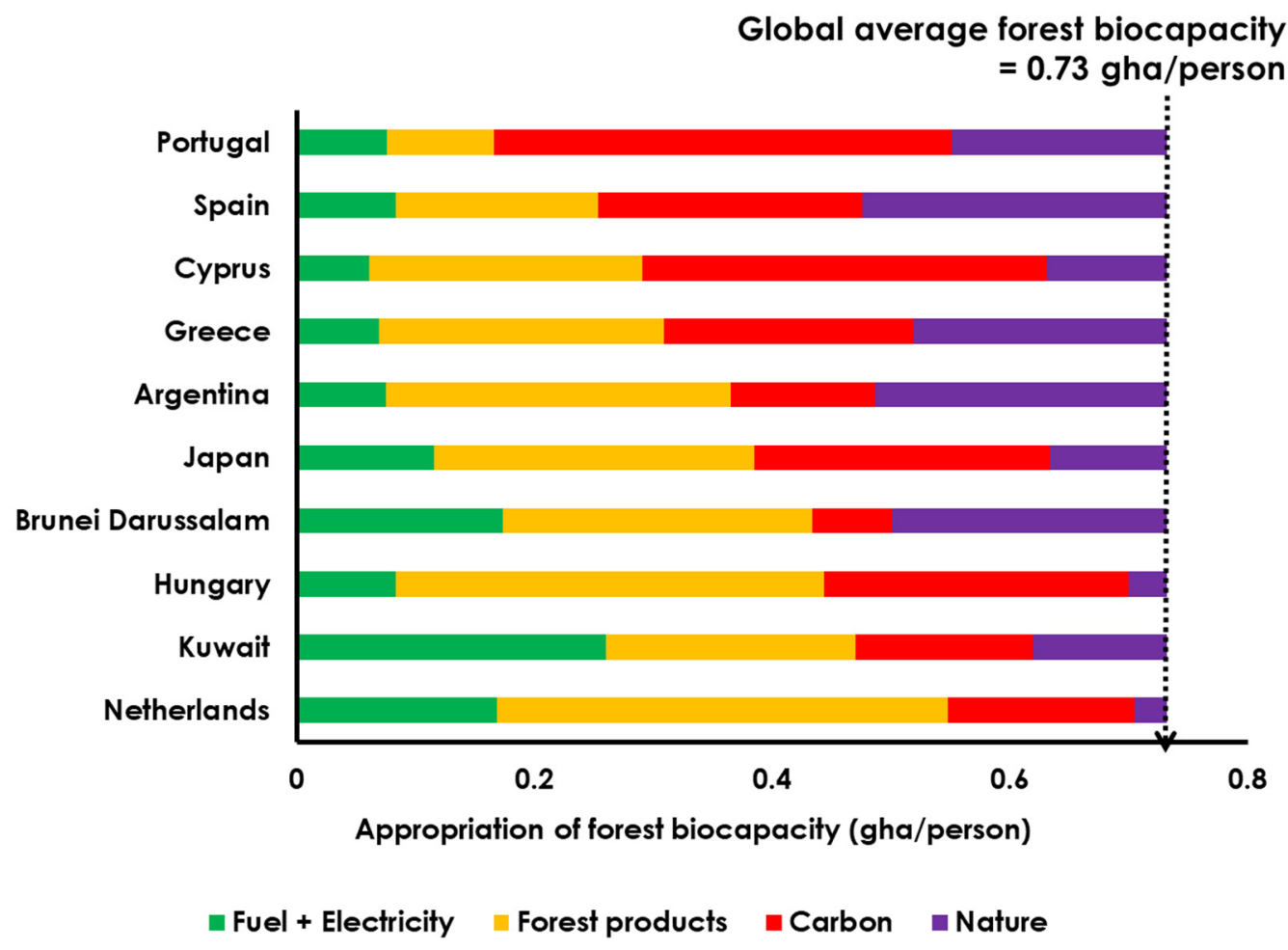

Figure 9. Appropriation of global average forest biocapacity according to different consumption types, for ten countries with Human Development Index (HDI) >0.8 (see Figure 8). The 'Fuel + Electricity' area is from Scenario 3 (Electrification + Synfuel).

\section{Discussion}

Based on this assessment, five high-HDI countries (Argentina, Cyprus, Greece, Portugal and Spain) have an energy and forest product consumption profile that —if adopted worldwide-could theoretically be met by high-tech renewably derived fuels, while theoretically preserving 50\% or more of the world's forest biocapacity. This finding offers a starting place for discussion of policy and behaviour change, by providing a culturally and economically diverse range of contemporary nations exhibiting 
consumption patterns that it may be possible to emulate globally in a sustainable way. Table 5 provides some characteristic information about the energy demand profiles in these exemplar countries, as well as the demand profiles from the highest and lowest HDI nations (Australia and Niger respectively). For context, as currently assessed, Australia's forest product footprint alone ( 0.89 gha/person) exceeds the global average forest biocapacity, leaving no room to equitably accommodate even its non-energy carbon footprint ( $0.34 \mathrm{gha} /$ person), let alone the additional renewable energy footprint $(0.17 \mathrm{gha} /$ person in the most optimistic case). Thus, Australia does not currently offer a consumption profile that can be sustainably emulated worldwide.

Table 5. Energy consumption patterns for exemplar and non-exemplar countries.

\begin{tabular}{|c|c|c|c|c|c|c|c|c|c|}
\hline \multirow{2}{*}{ Country } & \multirow{2}{*}{$\begin{array}{l}\text { Pop. } \\
\times 10^{6}\end{array}$} & \multirow{2}{*}{ HDI } & \multicolumn{2}{|c|}{$\begin{array}{l}\text { Final Energy Demand } \\
\text { \& Electrification } \\
\text { (Base Case) }\end{array}$} & \multicolumn{3}{|c|}{$\begin{array}{c}R E E F \\
\text { (gha/cap) }\end{array}$} & \multicolumn{2}{|c|}{$\begin{array}{l}\text { Additional Forest } \\
\text { Appropriation } \\
\text { (gha/cap) }\end{array}$} \\
\hline & & & $\begin{array}{l}\text { Total } \\
\text { (GJ/cap/y) }\end{array}$ & $\begin{array}{l}\text { Elec. } \\
(\%)\end{array}$ & $\begin{array}{l}\text { Base } \\
\text { Case }\end{array}$ & $\begin{array}{l}75 \% \\
\text { Elec. }\end{array}$ & $\begin{array}{c}75 \% \\
\text { Elec. }+ \\
\text { Synfuel }\end{array}$ & Forest & Carbon \\
\hline \multicolumn{10}{|c|}{ Top 5: REEF + forest footprint $<50 \%$ of forest biocapacity } \\
\hline Argentina & 41.1 & 0.83 & 63.2 & $17.6 \%$ & 0.75 & 0.20 & 0.07 & 0.29 & 0.12 \\
\hline Greece & 11.1 & 0.86 & 58.2 & $27.5 \%$ & 0.57 & 0.18 & 0.07 & 0.24 & 0.21 \\
\hline Cyprus & 1.13 & 0.85 & 51.3 & $24.6 \%$ & 0.54 & 0.16 & 0.06 & 0.23 & 0.34 \\
\hline Spain & 46.8 & 0.87 & 70.4 & $24.8 \%$ & 0.73 & 0.22 & 0.08 & 0.17 & 0.22 \\
\hline Portugal & 10.6 & 0.83 & 64.0 & $24.0 \%$ & 0.67 & 0.20 & 0.08 & 0.09 & 0.39 \\
\hline \multicolumn{10}{|c|}{ Other exemplars: $R E E F+$ forest footprint $>50 \%$ of forest biocapacity } \\
\hline Netherlands & 16.7 & 0.92 & 142.2 & $15.4 \%$ & 1.76 & 0.44 & 0.17 & 0.38 & 0.16 \\
\hline Kuwait & 3.25 & 0.82 & 220.0 & $21.7 \%$ & 2.42 & 0.69 & 0.26 & 0.21 & 0.15 \\
\hline Hungary & 9.98 & 0.82 & 70.5 & $17.8 \%$ & 0.83 & 0.22 & 0.08 & 0.36 & 0.26 \\
\hline $\begin{array}{c}\text { Brunei } \\
\text { Darussalam }\end{array}$ & 0.41 & 0.85 & 146.7 & $20.1 \%$ & 1.66 & 0.46 & 0.17 & 0.26 & 0.07 \\
\hline Japan & 127.3 & 0.89 & 97.2 & $27.7 \%$ & 0.96 & 0.30 & 0.12 & 0.27 & 0.25 \\
\hline \multicolumn{10}{|c|}{ Highest + lowest HDI countries } \\
\hline Australia & 23.1 & 0.93 & 147.4 & $22.1 \%$ & 1.61 & 0.46 & 0.17 & 0.89 & 0.34 \\
\hline Niger & 17.2 & 0.34 & 6.5 & $3.0 \%$ & 0.100 & 0.020 & 0.008 & 0.26 & 0.04 \\
\hline
\end{tabular}

The five best exemplars from Figure 9 are characterised by a relatively consistent level of total energy consumption (50-70 GJ/capita/y). Interestingly, Smil [18] quoted this exact range as being optimal for achieving the twin objectives of a fair share of energy worldwide and a satisfactory quality of life.

The remaining exemplar countries show different consumption profiles. The Netherlands has total energy consumption at $142 \mathrm{GJ} / \mathrm{capita} / \mathrm{y}$, akin to Australia's energy consumption and more than double the average of the other six countries. Coupled with a large forest footprint, the Netherlands represents a consumption profile that-if adopted globally—would demand a large fraction of the world's forests. Brunei Darussalam and Kuwait also present high energy consumption cases; however, modest forest product footprint and non-energy carbon footprints mean that these nations are technically able to be accommodated within biocapacity, albeit still demanding more than $50 \%$ of forest capacity. Japan and Hungary, meanwhile, have energy demands similar to the five exemplar countries, but their larger non-energy carbon and forest product footprints mean that the overall consumption profile for these two countries exceeds $50 \%$ of forest biocapacity.

In order to provide full context, Niger has been included as the lowest-HDI country out of the 127 considered in this analysis. The energy demand per capita in Niger is around one-tenth of the five main exemplar countries, and can be taken as an undesirable lower limit to energy demand. 
Of the five exemplars, the four European countries (Cyprus, Greece, Portugal and Spain) already have a high degree of electrification by present-day global standards, in the range of $24-28 \%$ of final energy demand. It is noteworthy, therefore, that the assumption made for Scenarios 2 and 3 would require approximately a trebling of electrification to get to the assumed level of $75 \%$ of final energy demand. Such an increase in electricity as a fraction of the overall energy mix is required to bring even these exemplar countries up to a globally transferrable consumption profile that could theoretically be met by renewable energy, while leaving some room for nature. The technical challenges posed by such a transition should not be underestimated. It should also be noted that an energy system so significantly dominated by renewable electricity would require very large amounts of energy storage, which would potentially reduce the EROI to below the values assumed in this analysis. The impact of electrification on storage needs and net energy yields is beyond the scope of this preliminary study, but warrants further investigation.

\section{Conclusions}

The conventional carbon footprint $(C F)$ is a useful tool for quantifying the extent to which the carbon emissions from - predominantly—fossil fuel energy consumption have placed humanity beyond the carrying capacity of global ecosystems. In essence the $C F$ can be viewed as a means to quantify the unsustainability of the present condition. In this paper we have presented a complementary tool, the renewable energy equivalent footprint $(R E E F)$, which can be used to quantify the footprint of an alternative energy supply, based on estimates of net yields from renewable energy sources, and accounting for cross-subsidisation of different energy types within the supply system.

By considering two different renewable energy sources (electricity and biofuel), the REEF method allows potential land area requirements to be calculated separately. This is important, for while it is plausible to consider renewable electricity production taking place somewhat passively with minimal competition with other productive land uses (e.g., offshore wind, onshore wind sharing land with grazing and cropping or natural ecosystems, rooftop solar, and desert solar farms), biofuel production requires suitable growing conditions that place it in likely competition with other bio-productive land. Assuming that grazing and cropping area will be non-negotiable in the future, we have presented the hypothetical biofuel area in relation to its most likely source of biocapacity: forest land.

Based on mid-range estimates of renewable energy yield and the present-day fraction of electricity to total energy demand, no high-HDI nation could have its future fuel demands met with a globally equitable share of forest biocapacity. It is only by invoking hypothetical alternative technology scenarios that a globally sustainable energy future can be envisaged. Even in the most optimistic scenario (coupling radical electrification of the energy system with use of high-yielding synthetic fuels), there is a very limited number of exemplar countries (five) with present-day energy consumption patterns that may be replicated across the globe in an approximately sustainable way. These five countries (Argentina, Cyprus, Greece, Portugal and Spain) exhibit a satisfactorily high HDI and a sufficiently small renewable energy footprint that it may spare more than $50 \%$ of the planet's forest biocapacity after considering the extraction of forest products, which also places a demand on these ecosystems. While it is not guaranteed that these exemplar countries currently have (or will have) a sustainable consumption pattern, nor whether the optimistic technological projections will prove possible in the future, at present they offer a useful starting place when attempting to envision the changes that may be required to create a sustainable and desirable future world, powered entirely by renewable energy.

The REEF method complements the conventional CF approach in several important ways. Firstly, the $C F$ can only conclude that there are currently no countries that exhibit both a satisfactory level of HDI $(>0.8)$ and a carbon assimilation area that can be met within a globally equitable share of forest land. Secondly, even in countries with a sufficiently low CF (almost all of which have HDI <0.6), the low carbon emissions do not constitute a sustainable energy system as long as these countries remain dependent on non-renewable fossil fuels. Finally, the $C F$ does not capture the required land footprint to replace non-renewable, carbon-intensive fossil fuels with carbon-neutral, renewable energy sources. 
The REEF method allows us to uncover - albeit only with optimistic assumptions about technology—at least a small handful of high-HDI nations whose energy consumption profile may be replicable worldwide without fossil fuels, while also quantifying the additional land footprint of the renewable energy infrastructure.

By considering both electricity and fuel energy in a simplified renewable energy mix, the REEF demonstrates that there is no possibility of a sustainable energy supply with today's low-yielding biofuels coupled with our modest degree of electrification; to achieve a sustainable and equitable energy future we must (a) treble the fraction of electricity in our supply mix, and (b) develop synthetic fuel sources to cover the remainder.

In summary, the REEF analysis demonstrates that a sustainable and desirable future powered by renewable energy: (i) may be possible, depending on the worldwide adoption of consumption patterns typical of several key exemplar countries; (ii) is highly dependent on major future technological development, such as radical electrification of the energy supply and the development of synthetic fuels; and (iii) is still likely to require appropriation of a substantial, but hopefully sustainable, fraction of the world's forest area or potentially an equivalent area of land of lower bio-productivity. This analysis has been conducted based on recent population numbers; further population growth will inevitably increase the burden on the world's forests and make a renewable energy future proportionally more difficult to attain and sustain.

Author Contributions: Conceptualisation, J.W., P.S. and R.C.; methodology, J.W. and S.M.; writing—original draft preparation, J.W. and R.C.; writing-review and editing, R.C., P.S. and L.C. All authors have read and agreed to the published version of the manuscript.

Funding: This research received no external funding.

Acknowledgments: L.C. is funded by an Irish Research Council/Marie Skłodowska-Curie CAROLINE Postdoctoral Fellowship (IRC-CLNE/2017/567).

Conflicts of Interest: The authors declare no conflict of interest.

\section{Appendix A}

A solution procedure for the six simultaneous equations is provided as follows.

Given

$$
\begin{gathered}
E R O I_{\text {elec }}=\frac{E_{\text {gross }}}{E_{\text {elec }}+F_{\text {elec }}} \\
E R O I_{\text {fuel }}=\frac{F_{\text {gross }}}{E_{\text {fuel }}+F_{\text {fuel }}} \\
E_{\text {gross }}=E_{\text {net }}+E_{\text {elec }}+E_{\text {fuel }} \\
F_{\text {gross }}=F_{\text {net }}+F_{\text {elec }}+F_{\text {fuel }} \\
R_{\text {elec }}=\frac{F_{\text {elec }}}{E_{\text {elec }}} \\
R_{\text {fuel }}=\frac{E_{\text {fuel }}}{F_{\text {fuel }}}
\end{gathered}
$$

Inserting (A3) and (A4) into (A1) and (A2) we obtain:

$$
\begin{aligned}
& E R O I_{\text {elec }}\left(E_{\text {elec }}+F_{\text {elec }}\right)=E_{\text {net }}+E_{\text {elec }}+E_{\text {fuel }} \\
& E R O I_{\text {fuel }}\left(E_{\text {fuel }}+F_{\text {fuel }}\right)=F_{\text {net }}+F_{\text {elec }}+F_{\text {fuel }}
\end{aligned}
$$

We can remove $F_{\text {elec }}$ and $E_{\text {fuel }}$ by using Equations (A5) and (A6). Doing this we obtain:

$$
E R O I_{\text {elec }}\left(E_{\text {elec }}+R_{\text {elec }} E_{\text {elec }}\right)=E_{\text {net }}+E_{\text {elec }}+R_{\text {fuel }} F_{\text {fuel }}
$$




$$
E R O I_{\text {fuel }}\left(F_{\text {fuel }}+R_{\text {fuel }} F_{\text {fuel }}\right)=F_{\text {net }}+F_{\text {fuel }}+R_{\text {elec }} E_{\text {elec }}
$$

Simplifying:

$$
\begin{gathered}
E_{\text {elec }}=\frac{E_{\text {net }}+R_{\text {fuel }} F_{\text {fuel }}}{\left[E R O I_{\text {elec }}\left(1+R_{\text {elec }}\right)-1\right]} \\
F_{\text {fuel }}=\frac{F_{\text {net }}+R_{\text {elec }} E_{\text {elec }}}{\left[E R O I_{\text {fuel }}\left(1+R_{\text {fuel }}\right)-1\right]} \\
F_{\text {fuel }}=\frac{F_{\text {net }}\left[E R O I_{\text {elec }}\left(1+R_{\text {elec }}\right)-1\right]+R_{\text {elec }} E_{\text {net }}}{\left[E R O I_{\text {fuel }}\left(1+R_{\text {fuel }}\right)-1\right]\left[E R O I_{\text {elec }}\left(1+R_{\text {elec }}\right)-1\right]-R_{\text {elec }} R_{\text {fuel }}} \\
E_{\text {elec }}=\frac{E_{\text {net }}\left[E R O I_{\text {fuel }}\left(1+R_{\text {fuel }}\right)-1\right]+R_{\text {fuel }} E_{\text {net }}}{\left[E R O I_{\text {fuel }}\left(1+R_{\text {fuel }}\right)-1\right]\left[E R O I_{\text {elec }}\left(1+R_{\text {elec }}\right)-1\right]-R_{\text {elec }} R_{\text {fuel }}}
\end{gathered}
$$

And using the expression of $F_{\text {elec }}$ and $E_{f u e l}$ from (A5) and (A6) we have:

$$
\begin{gathered}
F_{\text {elec }}=\frac{E_{\text {net }} R_{\text {elec }}\left[E R O I_{\text {fuel }}\left(1+R_{\text {fuel }}\right)-1\right]+R_{\text {elec }} R_{\text {fuel }} F_{\text {net }}}{\left[\operatorname{EROI}_{\text {fuel }}\left(1+R_{\text {fuel }}\right)-1\right]\left[E \operatorname{EOI}_{\text {elec }}\left(1+R_{\text {elec }}\right)-1\right]-R_{\text {elec }} R_{\text {fuel }}} \\
E_{\text {fuel }}=\frac{F_{\text {net }} R_{\text {fuel }}\left[E R O I_{\text {elec }}\left(1+R_{\text {elec }}\right)-1\right]+R_{\text {elec }} R_{\text {fuel }} E_{\text {net }}}{\left[E R O I_{\text {fuel }}\left(1+R_{\text {fuel }}\right)-1\right]\left[E R O I_{\text {elec }}\left(1+R_{\text {elec }}\right)-1\right]-R_{\text {elec }} R_{\text {fuel }}}
\end{gathered}
$$

Finally using (A3) and (A4) we obtain expressions for $E_{\text {gross }}$ and $F_{\text {gross }}$

$$
\begin{gathered}
E_{\text {gross }}=\frac{E R O I_{\text {elec }}\left(1+R_{\text {elec }}\right)\left[E_{\text {net }}\left[E R O I_{\text {fuel }}\left(1+R_{\text {fuel }}\right)-1\right]+F_{\text {net }} R_{\text {fuel }}\right]}{\left[\operatorname{EROI}_{\text {fuel }}\left(1+R_{\text {fuel }}\right)-1\right]\left[\operatorname{EROI}_{\text {elec }}\left(1+R_{\text {elec }}\right)-1\right]-R_{\text {elec }} R_{\text {fuel }}} \\
F_{\text {gross }}=\frac{E R O I_{\text {fuel }}\left(1+R_{\text {fuel }}\right)\left[F_{\text {net }}\left[E R O I_{\text {elec }}\left(1+R_{\text {elec }}\right)-1\right]+E_{\text {net }} R_{\text {elec }}\right]}{\left[E R O I_{\text {fuel }}\left(1+R_{\text {fuel }}\right)-1\right]\left[\operatorname{EROI}_{\text {elec }}\left(1+R_{\text {elec }}\right)-1\right]-R_{\text {elec }} R_{\text {fuel }}}
\end{gathered}
$$

\section{References}

1. UN Environment. Global Environment Outlook—GEO-6: Summary for Policymakers; UN Environment: Nairobi, Kenya, 2019. [CrossRef]

2. Rockström, J.; Steffen, W.L.; Noone, K.; Persson, Å.; Chapin, F.S., III; Lambin, E.; Lenton, T.M.; Scheffer, M.; Folke, C.; Schellnhuber, H.J.; et al. Planetary boundaries: Exploring the safe operating space for humanity. Ecol. Soc. 2009, 14, 32. [CrossRef]

3. Steffen, W.; Richardson, K.; Rockström, J.; Cornell, S.E.; Fetzer, I.; Bennett, E.M.; Biggs, R.; Carpenter, S.R.; De Vries, W.; De Wit, C.A.; et al. Planetary boundaries: Guiding human development on a changing planet. Science 2015, 347, 1259855. [CrossRef] [PubMed]

4. Aitken, R.; Watkins, L.; Kemp, S. Envisioning a sustainable consumption future. Young Consum. 2019, 20, 299-313. [CrossRef]

5. Rees, W.E. Ecological Footprints and Appropriated Carrying Capacity: What Urban Economics Leaves Out. Environ. Urban. 1992, 4, 121-130. [CrossRef]

6. Wackernagel, M.; Rees, W. Our Ecological Footprint: Reducing Human Impact on the Earth; New Society Publishers: Philadelphia, PA, USA, 1996.

7. Rees, W.E. Ecological Footprint, Concept of. In Encyclopedia of Biodiversity, 2nd ed.; Levin, S.A., Ed.; Academic Press: Pittsburgh, PA, USA, 2013; pp. 701-713.

8. Mohr, S.H.; Wang, J.; Ellem, G.; Ward, J.; Giurco, D. Projection of world fossil fuels by country. Fuel 2015, 141, 120-135. [CrossRef] 
9. Commonwealth of Australia. National Greenhouse Accounts Factors; Australian Government Department of Environment and Energy: Canberra, Australia, July 2017.

10. Scheidel, A.; Sorman, A.H. Energy transitions and the global land rush: Ultimate drivers and persistent consequences. Glob. Environ. Chang. 2012, 22, 588-595. [CrossRef]

11. Global Footprint Network. National Footprint Accounts; Global Footprint Network: Oakland, CA, USA, 2016.

12. Lin, D.; Hanscom, L.; Murthy, A.; Galli, A.; Evans, M.; Neill, E.; Mancini, M.S.; Martindill, J.; Medouar, F.-Z.; Huang, S.; et al. Ecological Footprint Accounting for Countries: Updates and Results of the National Footprint Accounts, 2012-2018. Resources 2018, 7, 58. [CrossRef]

13. Murphy, D.J.; Hall, C.A.; Dale, M.; Cleveland, C. Order from chaos: A preliminary protocol for determining the EROI of fuels. Sustainability 2011, 3, 1888-1907. [CrossRef]

14. Hall, C.A.; Lambert, J.G.; Balogh, S.B. EROI of different fuels and the implications for society. Energy Policy 2014, 64, 141-152. [CrossRef]

15. Hall, C.; Balogh, S.; Murphy, D. What is the minimum EROI that a sustainable society must have? Energies 2009, 2, 25-47. [CrossRef]

16. Moriarty, P.; Honnery, D. Can renewable energy power the future? Energy Policy 2016, 93, 3-7. [CrossRef]

17. Moran, D.D.; Wackernagel, M.; Kitzes, J.A.; Goldfinger, S.H.; Boutaud, A. Measuring sustainable development-Nation by nation. Ecol. Econ. 2008, 64, 470-474. [CrossRef]

18. Smil, V. Energy in Nature and Society: General Energetics of Complex Systems; MIT Press: Cambridge, MA, USA, 2008.

Publisher's Note: MDPI stays neutral with regard to jurisdictional claims in published maps and institutional affiliations. 